Hirofumi Yano MD, Masuhiko Takaori MD

\title{
The microcirculation during enflurane and isoflurane anaesthesia in dogs
}

The effects of enflurane and isoflurane of 0.75 and $1.5 \mathrm{MAC}$ on capillary blood flow were studied by the microsphere $(9$ $\pm 1 \mu \mathrm{m}$ in diameter) method in two groups of seven dogs. Simultaneously, changes in the arteriolo-venular shunt were studied by collection of venous blood at a rate of $4.8 \mathrm{ml} \cdot \mathrm{min}^{-1}$ for two minutes. Enflurane anaesthesia at $0.75 \mathrm{MAC}$ decreased capillary blood flow in the thyroid glands ( $35 \%$ of control), left and right ventricular wall (59\% and 50\%), adrenal gland (59\%), liver (63\%), spleen (56\%), pancreas (35\%), omentum (20\%), and small intestine (60\%) and at $1.5 \mathrm{MAC}$ it decreased further in the thyroid glands (15\%), left and right ventricular wall $(31 \%$ and $32 \%)$, adrenal gland (42\%), liver (47\%), spleen (31\%), pancreas (23\%), omentum (20\%), stomach (45\%), and small intestine (54\%). No marked changes were noted in the brain, kidney, large intestine or skeletal muscle. The arteriolovenular shunt was decreased in the kidney from an initial rate of 12.1 to $3.8 \%$ at $0.75 \mathrm{MAC}$ and to $2.5 \%$ at $1.5 \mathrm{MAC}$ enflurane. In contrast, during isoflurane anaesthesia, capillary blood flow remained unchanged, except for a decrease to the thyroid glands (43\%) and right ventricular wall (74\%) during 1.5 MAC anaesthesia. However, the arteriolo-venular shunt was increased in the brain from 12.0 to $29.7 \%$ and $33.0 \%$ during 0.75 and 1.5 MAC isoflurane anaesthesia, respectively. It also increased from 25.0 to $41.0 \%$ and $46.3 \%$ in the skeletal muscle, and from 8.9 to $19.9 \%$ and $17.4 \%$ in the whole systemic circulation. These data indicate that capillary blood flow is better preserved during isoflurane than during enflurane anaesthesia, but is associated with increased arteriolo-venular shunting.

\section{Key words}

ANAESTHETICS, VOLATILE: enflurane, isoflurane;

BLOOD: flow;

MEASUREMENT: blood flow, microspheres.

From the Department of Anesthesiology, Kawasaki Medical School, Kinki Central Hospital.

Address correspondence to: Dr. Hirofumi Yano, Department of Anesthesiology, Kinki Central Hospital, 3-1 Kurumazuka, Itami-City, Hyogo-ken, Japan 664.

Accepted for publication 14th October, 1993.
Les effets de l'enfurane et de lisoflurane 0,75 et 1,5 MAC sur le débit capillaire sont étudiés par la méthode des microsphères $(9 \pm 1 \mu m$ de diamètre) chez deux groupes de sept chiens. Simultanément, les altérations du shunt artériolo-veinulaire sont étudiées par la collecte de sang veineux à la vitesse de $4,8 \mathrm{ml} \cdot \mathrm{min}^{-1}$ pendant deux minutes. L'anesthésie à l'enflurane 0,75 MAC diminue le débit capillaire de la glande thyroïde (35\% du contrôle), des parois ventriculaires gauche et droite (59 et $50 \%)$, de la surrénale (59\%), du foie (63\%), de la rate (56\%), du pancréas (35\%), de l'épiploon (20\%) et de lintestin (60\%); à 1,5 MAC, la baisse saccentue dans la thyroïde (15\%), les parois ventriculaire gauche et droite $(31 \%$ et $32 \%)$, la surrénale $(42 \%)$, le foie $(47 \%)$, la rate $(31 \%)$, le pancréas $(23 \%)$, l'épiploon (20\%), l'estomac (45\%) et l'intestin grêle (54\%). On ne note pas de changements au cerveau, au rein, au gros intestin et au muscle squelettique. Le shunt artériolo-veinulaire diminue au rein de 12,1 à $3,8 \%$ à $0,75 \mathrm{MAC}$ et à $2,5 \%$ à $1,5 \mathrm{MAC}$. Par contre, avec l'anesthésie à l'isoflurane, le débit capillaire demeure inchangé, à l'exception d'une baisse dans la thyroïde (43\%) et la paroi ventriculaire droite $(74 \%)$ pendant l'anesthésie à 1,5 MAC. Cependant, le shunt artériolo-veinulaire augmente au cerveau de $12,0 \%$ à $29,7 \%$ et $33,0 \%$ respectivement sous isoflurane 0,75 et 1,5 MAC. Il augmente aussi de $25,0 \%$ à $41,0 \%$ et $46,3 \%$ dans le muscle squelettique, et de $8,9 \%$ à $19,9 \%$ et $17,4 \%$ dans la circulation systémique. Ces données montrent que le débit capillaire est mieux préservé pendant l'anesthésie à l'soflurane que pendant l'anesthésie à l'enflurane, mais que l'anesthésie à l'isoflurane est associée avec une augmentation du shunt artériolo-veinulaire.

Enflurane and isoflurane, which are structural isomers, have different cardiovascular effects. Enflurane depresses myocardial contractility and cardiac output in a dosedependent fashion. 1,2 Although the effect of isoflurane on myocardial contractility is still controversial, ${ }^{3,4}$ candiac output can be well maintained since systemic vascular resistance is decreased concomitantly. ${ }^{5}$ Many studies have compared the cardiovascular effects of these anaesthetics, but little has been written about their microcirculatory effects.

In a previous study, ${ }^{6}$ we compared the effects of enflurane and isoflurane on capillary blood flow and 
arteriolo-venular shunt, and differences in the effects of both anaesthetic agents on the nutrient supply to several organs were studied in dogs. However, definite conclusions could not be drawn because of the highly dispersed values of some variables. Therefore, the experiment was repeated.

\section{Methods}

\section{Subjects and preparation}

Twenty mongrel dogs of either sex, weighing 9.5-13.0 $\mathrm{kg}$, were anaesthetized with ketamine $\left(2 \mathrm{mg} \cdot \mathrm{kg}^{-1} \dot{i v}\right)$ and their tracheas were intubated with a cuffed tracheal tube. Their lungs were ventilated with $70 \%$ nitrous oxide in oxygen by a volume preset respirator (R60. Aika Instruments Co., Tokyo, Japan) with a tidal volume of 15 $\mathrm{ml} \cdot \mathrm{kg}^{-1}$ and a respiratory rate of $12 \mathrm{~min}^{-1}$. An electric blanket was used to maintain the animal's rectal temperature at $37-38^{\circ} \mathrm{C}$. The ECG was monitored with lead II. Teflon $i v$ catheters $(20 \mathrm{ga})$ were inserted directly into the left internal maxillary vein, which drains venous blood from the brain, into the right femoral vein, and into the left renal vein via the testicular (or ovarian) vein after laparotomy, respectively. Then, 6-Fr polyvinyl catheters were inserted into the external iliac artery via the left femoral artery, into the pulmonary artery via the right jugular vein, into the left atrium after left thoracotomy, and into the trunk of the portal vein via a branch of the lienal vein after the laparotomy. The catheters were fixed to each vessel with biological glue without disturbing blood flow, and they were used for the measurement of blood pressure and collection of blood.

After the experimental setup was completed, arterial blood was analyzed to assess acid-base balance and pulmonary gas exchange. The $\mathrm{PaO}_{2}, \mathrm{PaCO}_{2}$ and $\mathrm{pH}$ were maintained at over $100 \mathrm{mmHg}, 35 \pm 5 \mathrm{mmHg}$, and $7.40 \pm 0.05$ by adjusting the tidal volume and/or infusion of the alkalinizing drug. All animals were left in place for $\mathbf{4 5} \mathrm{min}$ to allow the circulation to stabilize.

\section{Experimental groups}

The animals were divided into three groups randomly. Six animals of $10.6 \pm 0.9 \mathrm{~kg}$ body weight (Group C) were anaesthetized with $70 \%$ nitrous oxide and $30 \%$ oxygen. Seven animals of $10.1 \pm 1.7 \mathrm{~kg}$ body weight (Group E) were anaesthetized with the nitrous oxide and oxygen mixture until completion of the first physiological measurements, details of which will be described later, and then either 0.75 or $1.5 \mathrm{MAC}$ enflurane gas was added to the nitrous oxide and oxygen gas mixture (MAC for dogs - enflurane $2.2 \%$, isoflurane $1.28 \%$ ). ${ }^{7}$ Selection of the concentration of enflurane or isoflurane to be used first was decided by a random number table before the series of experiments was started. The end-tidal concentration of enflurane or isoflurane was monitored continuously with an anaesthetic agent monitor (AA102 Acoma Co., Tokyo, Japan), the accuracy of which was compared with a value obtained by a gas chromatograph (Yanaco G-80 with an FID detector, Yanagimoto, Kyoto, Japan) on every experimental day. After $60 \mathrm{~min}$ was allowed for stabilization of the end-tidal concentration of enflurane, a second set of physiological measurements was made. Then, the concentration of inspired enflurane was changed to the alternate concentration and the stabilization period of $60 \mathrm{~min}$ was carried out before a third measurement was made.

In seven animals of $10.5 \pm 0.9 \mathrm{~kg}$ body weight (Group I), the same physiological measurements were made as in Group $\mathrm{E}$ during nitrous oxide and oxygen anaesthesia and the choice of either 0.75 or $1.5 \mathrm{MAC}$ isoflurane was made randomly before the experiment commenced. After the end-tidal concentration of isoflurane had stabilized, a second set of measurements was made. The inspired concentration of isoflurane was changed to the alternate concentration before a third set of measurements was made after stabilization of the end-tidal concentration of isoflurane.

The sequence of experiments of these three groups was randomly decided before the study was started. As abovementioned, the second and third physiological measurements were done at 60 and $120 \mathrm{~min}$ after the first measurement in Groups E and I. In Group C, these measurements were done at the same times.

\section{Physiological measurements}

Arterial blood gases and $\mathrm{pH}$ were measured with a blood gas analyzer (IL 1304 U.S.A.). Heart rate (HR) was measured from the R-waves of the ECG. Arterial pressure (AP) and left atrial pressure (LAP) were measured by a strain-gauge transducer (Nihon-Kohden TP-200T), and recorded on a multi-channel recorder (Nihon-Kohden WT-645G) with ECG. These mean pressures (MAP, MLAP) were determined electrically: After these measurements, either ${ }^{51} \mathrm{Cr}(70 \mu \mathrm{Ci})-{ }^{125} \mathrm{I}(20 \mu \mathrm{Ci})-$ or ${ }^{46} \mathrm{Sc}$ $(20 \mu \mathrm{Ci})$-labelled microspheres (3M Co., St. Paul, MN), $9.0 \pm 1.0 \mu \mathrm{m}$ in diameter, were injected into the left atrium via the implanted catheter. Prior to the injection, the microspheres were suspended in $2 \mathrm{ml}$ of physiological saline solution with $0.05 \mathrm{ml}$ of Tween $80^{\circledR}$ (Nakarai Chemical Co., Kyoto, Japan) to prevent aggregation. Blood sampling was begun at the moment of microsphere injection, and blood was collected simultaneously from the internal maxillary, renal, portal and femoral veins and the pulmonary artery via the inserted catheters at a rate of $4.8 \mathrm{ml} \cdot \mathrm{min}^{-1}$ for two minutes using constant withdrawal pumps. To compensate for blood loss of 48 
$\mathrm{ml}$ for the measurements and to avoid the influences of homologous blood transfusion, a volume of $6 \%$ dextran$70^{\circledR}$ solution $\left(\mathrm{MW}=70 \times 10^{3}\right)$ equal to the withdrawn blood was infused immediately after the blood collection. The amounts of microspheres in the collected blood were measured by an auto-gamma scintillation spectrometer (5320, Packard Instrument Co. Downers Glove, IL). Then, the numbers of microspheres shunted through each organ $\left(A_{S}\right)$ were measured in the brain, kidney, all of the splanchnic organs and the muscles of the pelvic limb. The radioactivity of the microspheres shunted through the systemic circulatory organs $\left(A_{S A}\right)$ was also measured in the same manner as in $A_{S}$ on the basis of the radioactivity of the blood withdrawn from the pulmonary artery. The same measurements were repeated using different anaesthetic concentrations of either enflurane or isoflurane at 60 and $120 \mathrm{~min}$ after the first measurements. Microspheres labelled with different isotopes, either ${ }^{51} \mathrm{Cr}$, ${ }^{125} \mathrm{I}$ or ${ }^{46} \mathrm{Sc}$, were used randomly for the three measurements.

Simultaneously with these measurements, cardiac output was determined by the method of Archie et al. ${ }^{8}$ Briefly, immediately after injection of the microspheres into the left atrium, arterial blood was collected from the external iliac artery at a constant flow rate (19 $\mathrm{ml} \cdot \mathrm{min}^{-1}$ ) for $15 \mathrm{sec}$. Cardiac output was calculated from the radioactivity of all of the injected and collected microspheres and the withdrawing speed. In addition, the cardiac index (CI) was calculated from the cardiac output and the body surface area of each dog. ${ }^{9}$

At the end of the experiment, ventricular fibrillation was induced electrically in the animals. Fourteen organs (Table II), including the four organs associated with measurement of the arteriolo-venular shunt, were removed and weighed. These organs were dissected into several small pieces and were placed in a counting vial. Samples were collected from the same part of each organ in every experiment. The radioactivity and weight of the samples were then measured and the total radioactivity of each organ $\left(A_{0}\right)$ was calculated from them. Capillary blood flow, the fractional distribution of the cardiac output of each organ and the shunt rate were obtained using the following equations:

$$
\begin{array}{r}
\text { Capillary blood flow }=A_{O} / A_{I} \times C O \times 100 / \text { organ } \\
\text { weight }\left(\mathrm{ml} \cdot \min ^{-1} \cdot 100 \mathrm{~g}^{-1}\right)
\end{array}
$$

Fractional distribution of the cardiac output

$$
=A_{0} / A_{1} \times 100(\%)
$$

Shunt rate (each organ) $=A_{S} /\left(A_{0}+A_{S}\right) \times 100(\%)$

Shunt rate (all of the systemic circulatory organs)

$$
=A_{S A} / A_{1} \times 100(\%)
$$

where $A_{1}$ is the radioactivity of the injected microspheres for each measurement and $\mathrm{CO}$ is the cardiac output. They were calculated in each stage by resolving the radioactivity of each isotope. Capillary blood flow was measured from the radioactivity of microspheres trapped in the organ and was presented as the blood flow per $100 \mathrm{~g}$ of wet tissue. Since the liver is nourished by the hepatic artery and the portal vein, the capillary blood flow of the liver was estimated from the summed radioactivity of microspheres trapped in the liver and all of the splanchnic organs.

All data are presented as the mean and SD. Paired Student's $t$ test was used to analyze the changes in variables from the initial value in each group. Comparisons between the $\mathrm{E}$ and $\mathrm{I}$ groups were analyzed by analysis of variance. Significance was assumed at $P<0.05$.

\section{Results}

The $\mathrm{PaO}_{2}, \mathrm{PaCO}_{2}, \mathrm{pH}$ and the base excess were similar among the three groups throughout the experiment.

No marked change was observed in haemodynamic variables, i.e., $\mathrm{HR}, \mathrm{AP}, \mathrm{LAP}$ and $\mathrm{CI}$, throughout the experiment in Group C. In Group E, however, HR decreased to 77 and $68 \%$ of the initial values and MAP decreased to 64 and $48 \%$ during 0.75 and 1.5 MAC enflurane anaesthesia. The MLAP increased to $178 \%$ during 1.5 MAC anaesthesia and $\mathrm{CI}$ decreased to 70 and $57 \%$ during 0.75 and $1.5 \mathrm{MAC}$ anaesthesia.

In Group I, HR decreased to 81 and $73 \%$ of the initial values, MAP decreased to 75 and 55\%, and MLAP increased to 152 and $193 \%$ during 0.75 and 1.5 MAC anaesthesia. The changes in MAP and $\mathrm{CI}$ during 0.75 MAC isoflurane were less than those during 0.75 MAC enflurane anaesthesia (Table I).

The capillary blood flow in various organs remained unchanged in Group C, but decreased from the initial values in most organs after enflurane was added to the inspiratory gas. During $0.75 \mathrm{MAC}$, enflurane decreased to $35 \%$ of the control in the thyroid glands, $59 \%$ in the left ventricular wall, $50 \%$ in the right ventricular wall, $59 \%$ in the adrenal glands, $63 \%$ in the liver, $56 \%$ in the spleen, $35 \%$ in the pancreas, $20 \%$ in the omentum and $60 \%$ in the small intestine, and at 1.5 MAC enflurane, decreased further to $15 \%$ in the thyroid glands, $31 \%$ in the left ventricular wall, $32 \%$ in the right ventricular wall, $42 \%$ in the adrenal glands, $47 \%$ in the liver, $31 \%$ in the spleen, $23 \%$ in the pancreas, $20 \%$ in the omentum, $45 \%$ in the stomach and $54 \%$ in the small intestine.

In Group I, in contrast, no marked changes in the capillary blood flow were observed, except for a decrease to $43 \%$ of the control in the thyroid glands and to $74 \%$ in the right ventricular wall during $1.5 \mathrm{MAC}$ anaesthesia. In the right ventricular wall, the change in the capillary blood flow during 1.5 MAC isoflurane was less than that 
TABLE I Respiratory and haemodynamic changes in each group (mean \pm SD)

\begin{tabular}{|c|c|c|c|c|c|c|c|c|c|}
\hline & \multicolumn{3}{|l|}{ Group C } & \multicolumn{3}{|l|}{ Group E } & \multicolumn{3}{|l|}{ Group I } \\
\hline & Initial & $\begin{array}{l}60 \text { min } \\
\text { after }\end{array}$ & $\begin{array}{l}120 \mathrm{~min} \\
\text { after }\end{array}$ & Initial & $0.75 \mathrm{MAC}$ & $1.50 M A C$ & Initial & $0.75 M A C$ & $1.50 \mathrm{MAC}$ \\
\hline $\mathrm{PaO}_{2}(\mathrm{mmHg})$ & $108 \pm 4$ & $115 \pm 6$ & $110 \pm 4$ & $117 \pm 14$ & $116 \pm 22$ & $109 \pm 26$ & $127 \pm 19$ & $124 \pm 19$ & $124 \pm 15$ \\
\hline $\mathrm{PaCO}_{2}(\mathrm{mmHg})$ & $33.4 \pm 3.1$ & $32.4 \pm 3.9$ & $31.7 \pm 3.8$ & $30.3 \pm 4.4$ & $32.1 \pm 3.3$ & $30.7 \pm 3.3$ & $33.9 \pm 5.7$ & $35.6 \pm 5.9$ & $32.6 \pm 6.0$ \\
\hline $\mathrm{pH}$ & $7.40 \pm 0.03$ & $37.38 \pm 0.05$ & $7.38 \pm 0.04$ & $7.40 \pm 0.05$ & $57.39 \pm 0.04$ & $7.38 \pm 0.03$ & $7.41 \pm 0.07$ & $7.39 \pm 0.06$ & $7.40 \pm 0.06$ \\
\hline \multicolumn{10}{|l|}{ Base excess } \\
\hline$\left(\mathrm{mEq} \cdot \mathrm{L}^{-1}\right)$ & $-3.0 \pm 1.2$ & $-4.9 \pm 1.9$ & $-4.9 \pm 1.7$ & $-4.6 \pm 2.5$ & $-4.7 \pm 1.3$ & $-5.9 \pm 1.3$ & $-2.5 \pm 3.8$ & $-3.5 \pm 2.4$ & $-3.7 \pm 2.5$ \\
\hline HR (beat $\cdot \min ^{-1}$ ) & $197 \pm 30$ & $193 \pm 35$ & $186 \pm 21$ & $193 \pm 23$ & $148 \pm 18 \dagger$ & $132 \pm 14 \dagger$ & $189 \pm 24$ & $154 \pm 7^{*}$ & $138 \pm 9 \dagger$ \\
\hline MAP (mmHg) & $116 \pm 8$ & $115 \pm 11$ & $114 \pm 8$ & $118 \pm 11$ & $76 \pm 19^{+}$ & $57 \pm 18 \dagger$ & $127 \pm 15$ & $95 \pm 14 t \ddagger$ & $70 \pm 9+$ \\
\hline MLAP (mmHg) & $5.3 \pm 1.9$ & $5.5 \pm 1.7$ & $4.9 \pm 1.8$ & $4.1 \pm 1.9$ & $4.8 \pm 2.7$ & $7.3 \pm 3.1^{*}$ & $2.7 \pm 1.8$ & $4.1 \pm 1.5^{*}$ & $5.2 \pm 1.1 \dagger$ \\
\hline $\mathrm{CI}\left(\mathrm{L} \cdot \mathrm{min}^{-1} \cdot \mathrm{m}^{-2}\right)$ & $4.0 \pm 1.6$ & $4.3 \pm 0.7$ & $3.8 \pm 0.9$ & $4.4 \pm 1.6$ & $3.1 \pm 1.1^{*}$ & $2.5 \pm 0.8^{*}$ & $3.6 \pm 0.8$ & $3.8 \pm 1.2 \ddagger$ & $3.5 \pm 1.8$ \\
\hline
\end{tabular}

Significantly different from the initial value $\left(^{*}=0.01<P<0.05, \dagger=P<0.001\right.$ ). Comparison of changes in Groups $\mathrm{E}$ and $\mathrm{I}$ after inhalation ( $\downarrow=$ $0.01<P<0.05)$. HR $=$ heart rate; $\mathrm{MAP}=$ mean arterial pressure; $\mathrm{MLAP}=$ mean left atrial pressure; $\mathrm{CI}=$ cardiac index.

TABLE II Capillary blood flows in various organs in each group (mean \pm SD)

\begin{tabular}{|c|c|c|c|c|c|c|c|c|c|}
\hline & \multicolumn{3}{|l|}{ Group C } & \multicolumn{3}{|l|}{ Group $E$} & \multicolumn{3}{|l|}{ Group I } \\
\hline & Initial & $\begin{array}{l}60 \mathrm{~min} \\
\text { after }\end{array}$ & $\begin{array}{l}120 \mathrm{~min} \\
\text { afier }\end{array}$ & Initial & $0.75 M A C$ & $1.50 \mathrm{MAC}$ & Initial & $0.75 M A C$ & $1.50 \mathrm{MAC}$ \\
\hline Brain & $56 \pm 24$ & $51 \pm 21$ & $44 \pm 17$ & $58 \pm 20$ & $49 \pm 12$ & $60 \pm 32$ & $69 \pm 46$ & $69 \pm 47$ & $93 \pm 49$ \\
\hline Thyroid glands & $78 \pm 25$ & $83 \pm 32$ & $71 \pm 18$ & $96 \pm 32$ & $34 \pm 17 \dagger$ & $14 \pm 5 \dagger$ & $100 \pm 59$ & $63 \pm 35$ & $43 \pm 24^{*}$ \\
\hline Ventricular wall (left) & $165 \pm 64$ & $170 \pm 65$ & $168 \pm 74$ & $205 \pm 71$ & $120 \pm 52^{*}$ & $63 \pm 33 \dagger$ & $202 \pm 89$ & $189 \pm 71$ & $132 \pm 29$ \\
\hline \multicolumn{10}{|l|}{ Ventricular wall } \\
\hline (right) & $111 \pm 44$ & $107 \pm 19$ & $107 \pm 37$ & $147 \pm 59$ & $73 \pm 32^{*}$ & $47 \pm 24^{*}$ & $107 \pm 38$ & $89 \pm 73$ & $79 \pm 35^{*} t$ \\
\hline Kidney (left) & $305 \pm 87$ & $335 \pm 54$ & $355 \pm 31$ & $362 \pm 160$ & $271 \pm 59$ & $225 \pm 104$ & $434 \pm 228$ & $376 \pm 97$ & $307 \pm 118$ \\
\hline Adrenal (left) & $106 \pm 43$ & $97 \pm 8$ & $101 \pm 20$ & $146 \pm 74$ & $86 \pm 41 \dagger$ & $61 \pm 24^{*}$ & $139 \pm 49$ & $144 \pm 73$ & $135 \pm 121$ \\
\hline Liver & $145 \pm 33$ & $124 \pm 16$ & $109 \pm 15$ & $203 \pm 68$ & $127 \pm 52 \dagger$ & $96 \pm 43 \dagger$ & $187 \pm 77$ & $180 \pm 76 \ddagger$ & $139 \pm 52$ \\
\hline Spleen & $206 \pm 92$ & $181 \pm 59$ & $158 \pm 67$ & $225 \pm 117$ & $125 \pm 92^{*}$ & $70 \pm 56^{*}$ & $181 \pm 80$ & $228 \pm 140 \S$ & $137 \pm 55 \ddagger$ \\
\hline Pancreas & $89 \pm 17$ & $89 \pm 28$ & $64 \pm 16$ & $108 \pm 59$ & $38 \pm 18^{*}$ & $25 \pm 11 \dagger$ & $89 \pm 62$ & $66 \pm 28$ & $42 \pm 23$ \\
\hline Omentum & $16 \pm 13$ & $13 \pm 9$ & $9 \pm 4$ & $30 \pm 20$ & $6 \pm 3^{*}$ & $6 \pm 5^{*}$ & $18 \pm 13$ & $11 \pm 13$ & $9 \pm 12$ \\
\hline Stomach & $30 \pm 17$ & $25 \pm 8$ & $21 \pm 11$ & $29 \pm 20$ & $19 \pm 11$ & $13 \pm 7^{*}$ & $40 \pm 26$ & $36 \pm 18$ & $27 \pm 14$ \\
\hline Small intestine & $33 \pm 16$ & $33 \pm 10$ & $29 \pm 7$ & $52 \pm 16$ & $31 \pm 9 \dagger$ & $28 \pm 7^{*}$ & $40 \pm 20$ & $31 \pm 13$ & $30 \pm 11$ \\
\hline Large intestine & $12 \pm 4$ & $16 \pm 4$ & $18 \pm 2$ & $14 \pm 9$ & $14 \pm 7$ & $15 \pm 6$ & $19 \pm 20$ & $20 \pm 10$ & $27 \pm 16$ \\
\hline Skeletal muscle & $4 \pm 3$ & $3 \pm 1$ & $3 \pm 1$ & $3 \pm 2$ & $4 \pm 2$ & $2 \pm 1$ & $5 \pm 3$ & $5 \pm 3$ & $3 \pm 1$ \\
\hline
\end{tabular}

Significantly different from the initial value $(0 \mathrm{MAC})(*=0.01<P<0.05, \dagger=P<0.01)$. Comparison of changes in Groups $\mathrm{E}$ and $\mathrm{I}$ after inhalation $(\sharp=0.01<P<0.05, \S=P<0.01$ ). $\uparrow=$ all skeletal muscles of the right pelvic limb.

during 1.5 MAC enflurane. Furthermore, capillary blood flow in the liver and spleen was maintained mostly unchanged during isoflurane anaesthesia while it decreased during enflurane anaesthesia (Table II).

The fractional distribution of the cardiac output to various organs remained unchanged in Group C. In Group $\mathrm{E}$, it increased from 1.99 to $3.02 \%$ in the brain and from 0.38 to $0.73 \%$ in the large intestine during $1.5 \mathrm{MAC}$ anaesthesia. In the remaining organs, in contrast, it decreased with the increasing concentration of anaesthetic. In the thyroid glands, it decreased from 0.05 to $0.02 \%$ during $0.75 \mathrm{MAC}$ and further to $0.01 \%$ during $1.5 \mathrm{MAC}$. In the left and right ventricular walls, it decreased from
2.99 to $1.58 \%$ and from 1.22 to $0.65 \%$, respectively, in the liver from 28.94 to $22.74 \%$, in the spleen from 4.20 to $2.13 \%$ and in the pancreas from 1.13 to $0.46 \%$ during 1.5 MAC anaesthesia.

In Group I, the fractional distribution of the cardiac output changed in a similar manner to that in Group $\mathrm{E}$ in most organs. It increased in the brain from an initial 2.23 to $3.40 \%$ during $1.5 \mathrm{MAC}$ isoflurane. However, it decreased from 0.05 to $0.02 \%$ in the thyroid glands, from 29.17 to $22.68 \%$ in the liver, and from 0.54 to $0.19 \%$ in the omentum during 1.5 MAC isoflurane anaesthesia.

The shunt in the measured organs remained unchanged in Group C (Table III). In Group E, it decreased 
TABLE III Shunt rates through arteriolo-venular anastomosing vessels in various organs in each group (mean \pm SD)

\begin{tabular}{|c|c|c|c|c|c|c|c|c|c|}
\hline & \multicolumn{3}{|l|}{ Group C } & \multicolumn{3}{|l|}{ Group E } & \multicolumn{3}{|l|}{ Group I } \\
\hline & Initial & $\begin{array}{l}60 \mathrm{~min} \\
\text { afier }\end{array}$ & $\begin{array}{l}120 \mathrm{~min} \\
\text { affer }\end{array}$ & Initial & $0.75 M A C$ & $1.50 \mathrm{MAC}$ & Initial & $0.75 M A C$ & $1.50 \mathrm{MAC}$ \\
\hline Brain & $11.5 \pm 7.7$ & $16.9 \pm 15.1$ & $15.1 \pm 10.3$ & $17.5 \pm 10.0$ & $23.0 \pm 12.8$ & $14.3 \pm 4.8$ & $12.0 \pm 5.8$ & $29.7 \pm 7.7 \dagger$ & $33.0 \pm 9.4+\S$ \\
\hline Kidney & $10.6 \pm 3.4$ & $8.0 \pm 4.3$ & $10.4 \pm 9.2$ & $12.1 \pm 6.5$ & $3.8 \pm 2.8^{*}$ & $2.5 \pm 3.2^{*}$ & $11.9 \pm 7.8$ & $13.3 \pm 14.8$ & $8.4 \pm 6.5$ \\
\hline Splanchnic organs & $17.4 \pm 5.6$ & $12.9 \pm 1.5$ & $17.9 \pm 6.4$ & $26.9 \pm 18.5$ & $20.0 \pm 16.2$ & $18.6 \pm 17.4$ & $25.4 \pm 8.4$ & $28.9 \pm .22 .6$ & $34.3 \pm 15.8 \ddagger$ \\
\hline Skeletal muscleq & $13.1 \pm 8.9$ & $22.6 \pm 17.1$ & $21.4 \pm 15.2$ & $27.5 \pm 12.9$ & $26.7 \pm 11.1$ & $36.5 \pm 25.0$ & $25.0 \pm 14.2$ & $41.0 \pm 9.9^{*}$ & $46.3 \pm 15.7 \dagger$ \\
\hline $\begin{array}{l}\text { Whole systemic } \\
\text { circulation }\end{array}$ & $9.5 \pm 0.6$ & $11.6 \pm 7.4$ & $11.7 \pm 5.3$ & $11.3 \pm 7.9$ & $15.6 \pm 13.6$ & $10.6 \pm 4.1$ & $8.9 \pm 2.2$ & $19.9 \pm 10.4$ & $* 17.4 \pm 4.1 \dagger \S$ \\
\hline
\end{tabular}

Significantly different from the initial value $(0 \mathrm{MAC})(*=0.01<P<0.05, \dagger=P<0.01)$. Comparison of changes in Groups $\mathrm{E}$ and $\mathrm{I}$ after inhalation $(\ddagger=0.01<P<0.05, \S=P<0.01) . \uparrow=$ all skeletal muscles of the right pelvic limb.

in the kidney from an initial value of 12.1 to $3.8 \%$ during $0.75 \mathrm{MAC}$ and to $2.5 \%$ during $1.5 \mathrm{MAC}$ enflurane. No changes were noted in other organs.

In Group I, in contrast to Group E, the shunt value increased in the brain, skeletal muscle and whole systemic circulation. In the brain, it increased from an initial value of 12.0 to $29.7 \%$ and $33.0 \%$ during 0.75 and $1.5 \mathrm{MAC}$ isoflurane anaesthesia, respectively. It also increased from 25.0 to $41.0 \%$ and $46.3 \%$ in the skeletal muscle, and from 8.9 to $19.9 \%$ and $17.4 \%$ in the whole systemic circulation. The change in the shunt rate in the brain, splanchnic organs and whole systemic circulation was significantly greater than that during 1.5 MAC enflurane (Table III).

\section{Discussion}

The systemic capillary has a diameter of about $6 \mu \mathrm{m},{ }^{10}$ whereas the diameter of the systemic arteriolo-venular shunting vessels is wider than $10 \mu \mathrm{m} .{ }^{11}$ Fan et al. ${ }^{12} \mathrm{dem}$ onstrated that the arteriolo-venus shunt rate for $\emptyset 15 \mu \mathrm{m}$ microspheres was $<2 \%$ in the brain, myocardium, kidney, intestine and lung. They also reported that it remained unchanged even in acidotic states. The shunt rate for $\emptyset 9 \mu \mathrm{m}$ microspheres, in contrast, ranged from $3 \%$ in the myocardium to $24 \%$ in the splanchnic organs and it increased slightly in an acidotic state. ${ }^{12}$ As mentioned above, the $\varnothing 9 \mu \mathrm{m}$ microspheres used in this study seem most appropriate for the measurement of capillary flow and arteriolo-venular shunt flow in all organs, since they should be trapped mostly in the capillary beds and should pass through the arteriolo-venular anastomosing vessels.

In Group $\mathrm{C}$, all variables remained unchanged throughout the experiment. This means that long-standing anaesthesia (e.g., for eight hours) with a mixture of oxygen and nitrous oxide and artificial ventilation does not affect the capillary and arteriolo-venular shunting blood flows. In human volunteers, Calverley $e t$ al.$^{2}$ observed that cardiac output, which decreased after initiation of
1 MAC enflurane anaesthesia, returned toward the awake level gradually for the subsequent six hours. In the meantime systemic vascular resistance decreased and peripheral blood flow increased. Similar results have been reported in isoflurane anaesthesia. ${ }^{5}$ In our study, animals were anaesthetized with 0.75 and $1.50 \mathrm{MAC}$ of either enflurane or isoflurane for $60 \mathrm{~min}$. Therefore it was unlikely that the circulatory accommodation would occur in such short intervals of different depths of anaesthesia.

The CI remained unchanged during isoflurane anaesthesia, but it decreased in a dose-related fashion with enflurane (Table I). Very similar results have been reported in healthy human volunteers. ${ }^{13}$ Shimosato et al. ${ }^{5}$ demonstrated that $\mathrm{CI}$ remained unchanged at 1 MAC isoflurane for $90 \mathrm{~min}$ in human volunteers. It is well known that 1-2 MAC isoflurane has no effect upon myocardial performance in vivo., 413 This can be explained by the activation of beta sympathetic activity and a decrease in afterload due to peripheral vasodilatation. ${ }^{13}$ In contrast, enflurane may depress left ventricular function in a dose-dependent fashion. ${ }^{1,2}$ Again, in this study, the different cardiovascular responses to isoflurane and enflurane were demonstrated. Although a decrease in mean arterial pressure associated with both anaesthetics was observed, the change in Group I was less than that in Group E (Table I).

The capillary blood flow in the brain was unchanged during either enflurane or isoflurane anaesthesia (Table II). It has been reported that cerebral blood flow in dogs is not affected by either $3 \%$ enflurane ${ }^{14}$ or $1.4 \%$ isoflurane anaesthesia. ${ }^{15}$ The data obtained in this study agree with these reports. It has been demonstrated that cerebral blood flow can be maintained, by autoregulation, despite disturbances in systemic circulation. The fractional distribution of cardiac output in the brain increased during both 1.5 MAC enflurane and isoflurane in this study. Stullken et al. ${ }^{14}$ and Cucchiara et al. ${ }^{15}$ on the other hand, reported that cerebral blood flow increased during iso- 
flurane anaesthesia in dogs. Eger ${ }^{13}$ noted that, at 1.6 MAC isoflurane, the cerebral blood flow in human volunteers increased. Although our data indicated that cerebral capillary blood flow remained unchanged during isoflurane anaesthesia, the arteriolo-venular shunt flow increased, and thus total blood flow to the brain increased. It was presumed that the total blood flow to the brain increased during isoflurane anaesthesia and that the increased blood flow was shunted through arteriolovenular anastomoses. This response in the cerebral circulation might be controlled by the autoregulatory mechanism in the brain. ${ }^{16}$

In Group I, capillary blood flow in the ventricular wall remained unchanged except in the right ventricular wall during 1.5 MAC isoflurane. In Group E, however, it decreased with an increase in the inspired concentration of enflurane (Table II). This difference may be caused by the different effects of the two anaesthetics upon coronary perfusion. It has been observed that at up to 2 MAC isoflurane, myocardial blood flow was maintained ${ }^{17}$ due to dilatation of the coronary arterioles. ${ }^{18}$ In contrast, enflurane decreased the myocardial blood flow in a dose-related fashion as decreased ventricular function. ${ }^{1}$

The renal capillary blood flow was not altered during either enflurane or isoflurane anaesthesia (Table II). Cousins et al. ${ }^{19}$ noted a slightly decreasing trend in renal blood flow during enflurane anaesthesia in man. Gelman et al. ${ }^{17}$ reported, however, that the regional blood flow in the kidney remained unchanged during isoflurane anaesthesia in dogs. These observations agree with our findings. The arteriolo-venular shunt rate in the kidney decreased during enflurane anaesthesia, but remained unchanged during isoflurane anaesthesia (Table III). The decrease in the shunt rate during the enflurane anaesthesia might explain why enflurane has no influence on the autoregulation of the kidney and why the renal capillary blood flow tended to decrease slightly. Isoflurane, on the other hand, might impair the autoregulation of the kidney due to the increase in the arteriolo-venular shunting flow. Mazze et al. ${ }^{20}$ observed that renal blood flow decreased to $51 \%$ of the control during $0.5-1.0 \mathrm{MAC}$ isoflurane in man. Therefore, if an increase in the arteriolo-venular shunt during isoflurane anaesthseia as observed in this study also exists in man, isoflurane might decrease the oxygen supply to the renal tissue.

In the present study, the total hepatic capillary blood flow decreased during enflurane anaesthesia and the capillary blood flow of many splanchnic organs also decreased (Table II). These findings agree with previous studies. ${ }^{21,22}$ Hughes et al. ${ }^{21}$ observed that the hepatic arterial blood flow and the portal blood flow both decreased to about 50\% during $3 \%$ enflurane in dogs. On the other hand, isoflurane maintained the total hepatic and splanchnic capillary blood flow in this study (Table II). Gelman et al. ${ }^{23}$ demonstrated that the total hepatic blood flow was maintained during $2 \mathrm{MAC}$ isoflurane in dogs. However, in their study, the portal blood flow (i.e., splanchnic blood flow) decreased during 1-2 MAC isoflurane anaesthesia. The discrepancy between the two studies may depend on the differences in the control state; namely, Gelman used the waking state as a control, whereas we used the anaesthetized state with nitrous oxide and oxygen. Cardiac output is not decreased by 1-2 MAC isoflurane, since it has little effect upon myocardial function ${ }^{13}$ and it may dilate peripheral vessels in the splanchnic organs. However, it may be presumed that the arteriolo-venular shunting vessels of the splanchnic organs were also dilated during the isoflurane anaesthesia, since the change in the shunt rate in the splanchnic organs in Group I was much greater than that in Group E (Table III).

Capillary blood flow in the skeletal muscle remained unchanged in both Groups $\mathrm{E}$ and I. However, the arteriolo-venular shunt rate in the skeletal muscle increased in Group I. It may be inferred that isoflurane dilates the arteriolo-venular shunting vessels in the skeletal muscle as well as in other organs. This increase in the shunt rate might be one of the main sources of the increased arteriolo-venular shunt rate in the whole systemic circulation, since skeletal muscle constitutes a large part of the whole body.

In conclusion, the results obtained indicated that isoflurane might be more effective than enflurane for maintenance of the capillary blood flow in most organs. However, it was also observed that isoflurane increased the arteriolo-venular shunt in several organs. Consequently, effective blood supply to the tissue might remain unchanged or decrease slightly during isoflurane anaesthesia. Furthermore, the effect of isoflurane, which increases the arteriolo-venular shunt, might cause some adverse effects in some pathological conditions. For example, it might be related to the steal of the coronary circulation in patients with coronary artery disease. ${ }^{24}$

\section{References}

1 Merin RG, Kumazawa T, Luka NL. Enflurane depresses myocardial function, perfusion, and metabolism in the dog. Anesthesiology 1976; 45: 501-7.

2 Calverley RK, Smith NT, Prys-Roberts C, Eger EI II, Jones $C W$. Candiovascular effects of enflurane anesthesia during controlled ventilation in man. Anesth Analg 1978; 57: $619-28$.

3 Komai H, Rusy BF. Negative inotropic effects of isoflurane and halothane in rabbit papillary muscles. Anesth Analg 1987; 66: 29-33.

4 Stevens WC, Cromwell TH, Halsey MJ, Eger EI II. Shake- 
speare TF, Bahlman SH. The cardiovascular effects of a new inhalation anesthetic, Forane, in human volunteers at constant arterial carbon dioxide tension. Anesthesiology 1971; 35: 8-16.

5 Shimosato S, Carter JG, Kemmotsu O, Takahashi T. Cardiocirculatory effects of prolonged administration of isoflurane in nomocarbic human volunteers. Acta Anaesthesiol Scand 1982; 26: 27-30.

6 Yano H, Matsumoto N, Fukui A, Fujita Y, Sakai T, Takaori $M$. The effects of enflurane and isoflurane on the regional blood flow and the arteriovenous shunt in various organs in dogs. Masui 1988; 37: 667-77.

7 Quasha AL, Eger EI II, Tinker JH. Determination and applications of MAC. Anesthesiology 1980; 53: 315-34.

8 Archie JP Jr, Fixler DE, Ullyot DJ, Hoffman JIE, Utley $J R$, Carlson EL. Measurement of cardiac output with and organ trapping of radioactive microspheres. J Appl Physiol 1973; 35: 148-54.

9 Guyton AC, Jones CE, Coleman TG. Circulatory Physiology: Cardiac Output and Its Regulation. Philadelphia: W.B. Saunders Company, 1973; 12.

10 Folkow B, Neil E. Circulation. New York: Oxford University Press, 1971; 37.

11 Marcus $M L$, Heistad DD, Ehrhardt JC, Abboud FM. Total and regional cerebral blood flow measurement with 7-10-, 15-, 25-, and 50- $\mu \mathrm{m}$ microspheres. J Appl Physiol 1976; 40: 501-7.

12 Fan FC, Schuessler GB, Chen RYZ, Chien S. Determinations of blood flow and shunting of 9- and 15$\mu \mathrm{m}$ spheres in regional beds. Am J Physiol 1979; 237 . H25-H33.

13 Eger EI II. The pharmacology of isoflurane. $\mathrm{Br} J$ Anaesth 1984; 56: 71s-99s.

14 Stullken EH Jr, Milde JH, Michenfelder JD, Tinker JH. The nonlinear responses of cerebral metabolism to low concentrations of halothane, enflurane, isoflurane, and thiopental. Anesthesiology 1977; 46: 28-34.

15 Cucchiara RF, Theye RA, Michenfelder JD. The effects of isoflurane on canine cerebral metabolism and blood flow. Anesthesiology 1974; 40: 571-4.

16 Todd MM, Drummond JC. A comparison of the cerebrovascular and metabolic effects of halothane and isoflurane in the cat. Anesthesiology 1984; 60: 276-82.

17 Gelman S, Fowler KC, Smith LR. Regional blood flow during isoflurane and halothane anesthesia. Anesth Analg 1984; 63: 557-65.

18 Sill JC, Bove AA, Nugent $M$, Blaise GA, Dewey JD, Grabau $C$. Effects of isoflurane on coronary arteries and coronary arterioles in the intact dog. Anesthesiology 1987; 66: 273-9.

19 Cousins MJ, Greenstein LR, Hitt BA, Mazze RI. Metabolism and renal effects of enflurane in man. Anesthesiology 1976; 44: 44-53.
20 Mazze RI, Cousins MJ, Barr GA. Renal effects and metabolism of isoflurane in man. Anesthesiology 1974; 40: 536-42.

21 Hughes RL, Campbell D, Fitch W. Effects of enflurane and halothane on liver blood flow and oxygen consumption in the greyhound. Br J Anaesth 1980; 52: 1079-86.

22 Andreen $M$, Irestedt $L$. Effects of enflurane on splanchnic circulation. Acta Anaesthesiol Scand Suppl 1979; 71: 48-51.

23 Gelman S, Fowler KC, Smith LR. Liver circulation and function during isoflurane and halothane anesthesia. Anesthesiology 1984; 61: 726-30.

24 Reiz $S$, Bålfors $E$, Sørensen $M B$, Ariola $S J r$, Friedman A, Truedsson $H$. Isoflurane - a powerful coronary vasodilator in patients with coronary artery disease. Anesthesiology 1983; 59: 91-7. 